\title{
Zinc Oxide Nanoparticles (ZnONPs) photocatalyst using pulse laser ablation method for antibacterial in water polltude
}

\author{
Fatkhiyatus Sa'adah, Rizka Zakiyatul Miskiyah, and Ali Khumaeni* \\ Department of Physics, Faculty of Science and Mathematics, Diponegoro University, Semarang, Indonesia, ${ }^{*}$ khumaeni@fisika.fsm.undip.ac.id
}

\section{A R T I C LE IN F O}

\section{Article history:}

Received : 20 May 2020

Accepted : 6 June 2020

Available online : 10 June 2020

Keywords:

Zinc Oxide Nanoparticles

Laser Ablation

Antibacterial

\begin{abstract}
A B S T R A C T
Pulsed laser ablation method had been successfully performed to produce high-purity zinc oxide nanoparticles. A low-energy Nd:YAG laser beam, of 30 $\mathrm{mJ}$, was bombarding the zinc plate surface followed by ablating the plate to produce zinc oxide nanoparticles (ZnONPs) solution. Synthesis was carried out in aquades medium with a repetition rate variation of $5 \mathrm{~Hz}, 10 \mathrm{~Hz}$ and 15 Hz. Characterization of the ZnONPs was performed by employing XRD, FTIR, SEM-EDX, imageJ software, and UV-Vis spectroscopy. The image of SEM result that $\mathrm{ZnONPs}$ have around shape. The characterization results revealed that most of the ZnONPs are small size spherical particles with average diameter decreased from $23.63 \mathrm{~nm}, 12.13 \mathrm{~nm}$ and $5.59 \mathrm{~nm}$ as the repetition rate increased. Energy band gap of ZnONPs in range 3.1-3.2 eV verified of ultraviolaet absorbance. ZnONPs is activated by irradiating UV light so that photocatalyst reaction occurred. The testing of the antibacterial activity of ZnONPs using a liquid dilution method with nanoparticle concentrations of $40 \mathrm{ppm}, 60 \mathrm{ppm}$ and $80 \mathrm{ppm}$. The test results showed the percentage of degradation of Escherichia coli bacteria at concentrations of 40 ppm, $60 \mathrm{ppm}$ and $80 \mathrm{ppm}$ respectively at $89.60 \%, 97.76 \%$ and $98,70 \%$.
\end{abstract}

\section{Introduction}

Water pollution is one of the most serious concerns in environmental management. Water pollution is contributed by several pollutants originating from household, agricultural, medical, and industrial waste [1]. The polluted material accumulates in rivers and the sea in the form of hazardous waste such as bacteria [2-3]. On the other hand, water pollution by pathogenic bacteria is characterized by the presence of bacterial resistance. Water pollution by bacteria is triggered by a variety of pathogenic bacteria such as Escherichia coli (E coli)[4].

Solution of water pollutants polluted by $\mathrm{E}$ coli can be treated using the photocatalyst method. The photocatalyst method has proven to be effective in describing heavy metal and bacterial waste in a relatively short and clean time [5-8]. Photocatalyst material generally used to decompose bacterial and heavy metal waste is Zinc oxide nanoparticles (ZnONPs) [9-10].

Zinc oxide nanoparticles (ZnONPs) are one type of metal oxide that is widely used to overcome the problem of water pollutants [11-14]. ZnONPs have strong oxidation ability, good photocatalytic properties, chemical stability and recombination with other materials, bicompatibility, non-toxic, high light sensitivity [15] which is more effective, economical and environmentally friendly. Nanoparticles are able to increase specific surface area so that absorption of pollutants increases [16]. ZnONPs have the ability as antibacerial, self cleaning and heavy metal reduction [17].
The prevalent methods used to synthesize ZnONPs are precipitation method, sol-gel synthesis, sonochemical reactions, hydrothermal reactions and wet chemical method. All of those chemical methods can produce spherical and monodispersed nanocrystals with adjustable size and composition by controlling the nucleation and growth mechanisms during particle formation. However, the methods require complicated and expensive chemical processes [18].

The other method used to produce ZnONPs is pulse laser ablation method. Pulse laser ablation is a simple method for fabricating the metal nanoparticles without surfactant or chemical addition. In this method, Nd: YAG laser is used as an energy source for ablation a solid target material [19].

Synthesis of ZnONPs using pulse laser ablation methods has been done by Singh (2007). In this research, a high energy Nd: YAG laser with $100 \mathrm{~mJ}$ and repetition rate laser is $10 \mathrm{~Hz}$ was used. Yu (2017) also conducted research using a pulse laser ablation method which has an energy laser $300 \mathrm{~mJ}$ and repetition rate $15 \mathrm{~Hz}$. In that study, ZnONPs were able to produce particle size 40-120 nm. However, this researches has not tested the effect of using repetition rate laser and is still using high laser energy [20-21].

In this study, ZnONPs synthesized using the pulse laser ablation method as E coli antibacterial in polluted water. The synthesis process was conducted to investigate the laser repetition rate on 
the ZnONPs size at low laser energy. The lower laser energy was utilized to prevent the agglomeration.

\section{Methodology}

\subsection{Synthesis Zinc Oxide Nanoparticles}

In this study, zinc oxide nanoparticles was produced by pulse laser ablation method. A high-purity (of about 99.95\%) zinc plate was immersed into $10 \mathrm{ml}$ of deionized water in a petri dish. The target irradiation was done by using Neodymium yttrium aluminum garnet (Nd:YAG) laser beam (New Wave Research, with wavelength of $1084 \mathrm{~nm}$, and pulse duration of $7 \mathrm{~ns}$ ) focused on the zinc plate surface with energy of the laser arranged to $30 \mathrm{~mJ}$. The laser pulse repetition rate was varied to $5 \mathrm{~Hz}, 10 \mathrm{~Hz}$ and $15 \mathrm{~Hz}$ to produce zinc oxide nanoparticles colloidal solution. The experimental set up used in this work is shown in Figure 1.

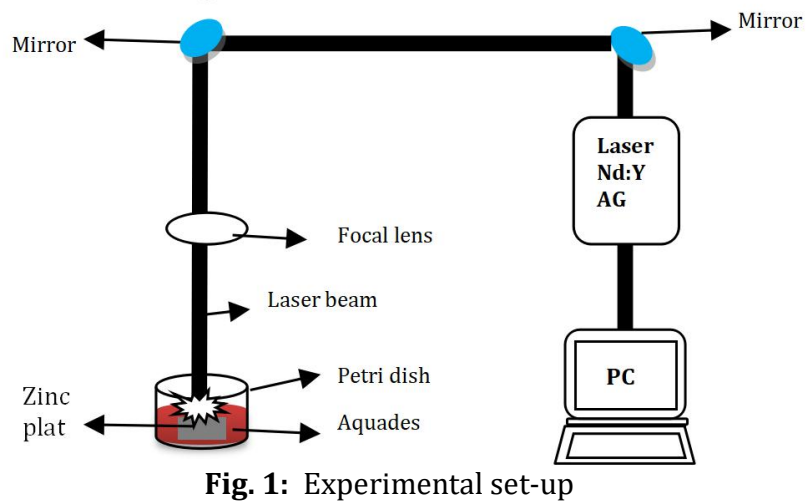

The laser beam will bombarded the sample surface during 60 minutes for any sample. In the synthesis process, the laser beam will be deflected with a mirror to the convex focus lens which has a focal distance of $3 \mathrm{~cm}$. During the shooting process, the petri dish containing the zinc plate is moved slowly to obtain homogeneous nanoparticles.

\subsection{Characterization Zinc Oxide Nanoparticles}

The synthesized ZnONPs were then characterized. To find out the absorbance level and energy band gap of ZnONPs, Ultraviolet Visible Light Spectroscopy (UV-Vis) test was performed. The XRay Diffraction test is performed to identify the crystalline phases and various oxides contained in ZnONPs. Fourier Transform Infra Red Spectrophotometer (FTIR) test was also carried out with the aim of identifying functional groups and compounds contained in ZnONPs.

In addition, morphological photograph of the ZnONPs was generated by utilizing Scanning Electron Microscopy - Energy Diffraction X-ray (SEM-EDX, JEOL JED-2300). The resulting image from SEM-EDX is then processed with image software to determine the distribution size of the ZnONPs produced.

\subsection{Application of ZnONPs}

ZnONPs testing as antibacterial in water polluted is carried out by utilizing the photocatalysts mechanism. This mechanism will function if ZnONPs have been activated. The activation process is carried out by making a $\mathrm{ZnO}$ nanoparticle solution from sample water to be tested with a concentration variation of $40 \mathrm{ppm}, 60 \mathrm{ppm}$ and $80 \mathrm{ppm}$. The solution is then irradiated with Ultraviolet (UV) light.
The irradiation process will occurred for 90 minutes and during the irradiation takes place, the solution will be stirred using a magnetic stirer.

\section{Results and Discussion}

ZnONPs were successfully synthesized using pulse laser ablation method with low energy laser and various repetition rate. The color of ZnONPs colloidal was changed from light to brown along with increasing number of repetition rate.

\subsection{Samples}

ZnONPs were produced from zinc plate (Nilaco, 99.95\%). ZnONPs synthesis by pulse laser ablation method begins when the Nd: YAG laser which has a wavelength (1064 nm, $7 \mathrm{~ns}$ ) is focused with a convex lens. The darker color of ZnONPs colloidal proves that a higher concentration of nanoparticles were produced [27]. ZnONPs synthesized shown in figure 2.

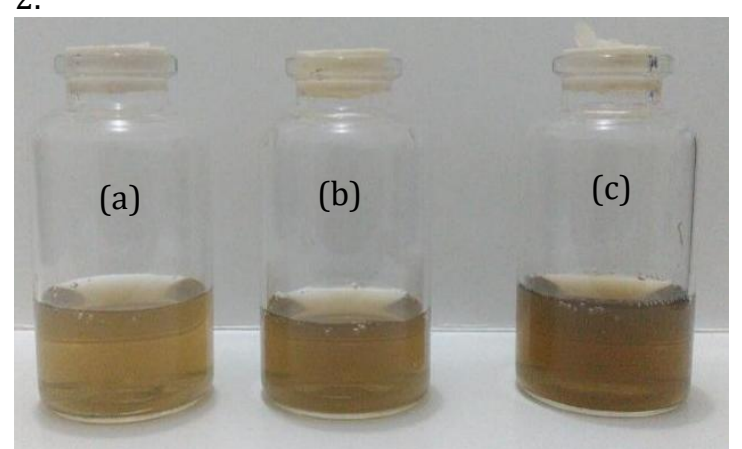

Fig. 2: ZnONPs synthesized with laser pulse frequency (a) $5 \mathrm{~Hz}$, (b) $10 \mathrm{~Hz}$ and (c) $15 \mathrm{~Hz}$

\subsection{XRD analysis}

The chemical composition of samples is provided in Table 1. The XRD pattern obtain for the samples with $15 \mathrm{~Hz}$ repetition frequency. The difraction peak at $31.32 \mathrm{o}, 34.2 \mathrm{o}, 36.1 \mathrm{o}, 47.3 \mathrm{o}, 56.4 \mathrm{o}, 62.7 \mathrm{o}, 66.1 \mathrm{o}$, $67.7 \mathrm{o}$, and $68.9 \mathrm{o}$. The Crystal Planes respectively in (100), (002), (101), (012), (110) and (013). The corresponding XRD pattern show the formation of pure ZnONPs.

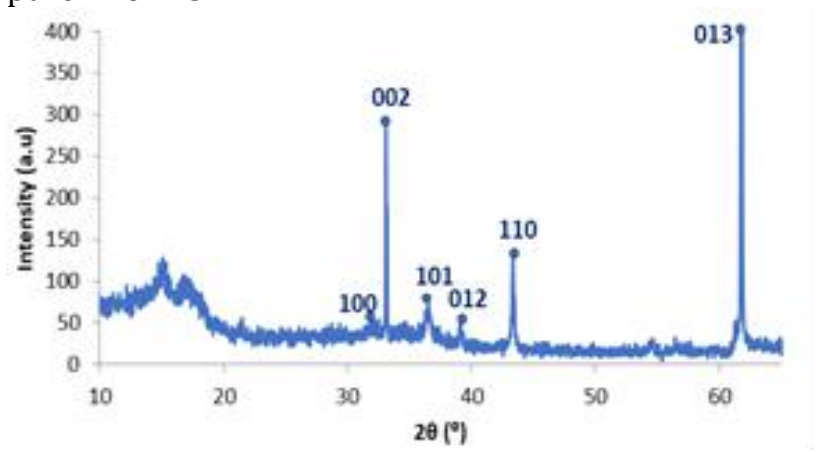

Fig. 3: The XRD spectrum of $\mathrm{ZnO}$ colloid nanoparticles results from the synthesis of the pulse laser ablation method

\subsection{Morphology Analysis of ZnONPs}

To find out the morphology of ZnONPs synthesized by the laser laser ablation method, Scanning Electron Microscopy (SEM) test was performed. The SEM test was carried out by dropping colloidal ZnONPs into a $1 \mathrm{~mm} \times 1 \mathrm{~mm}$ silicon carbide (SiC) wafer plate. Previously, the SiC plate was cleaned first. Then the colloidal ZnONPs are dripped with room temperature (around 30o C) for 24 hours. 
ZnONPs that have been deposited on a SiC plate are then tested by SEM. SEM test result that the particles produced for each laser shot frequency produce spherical shapes.

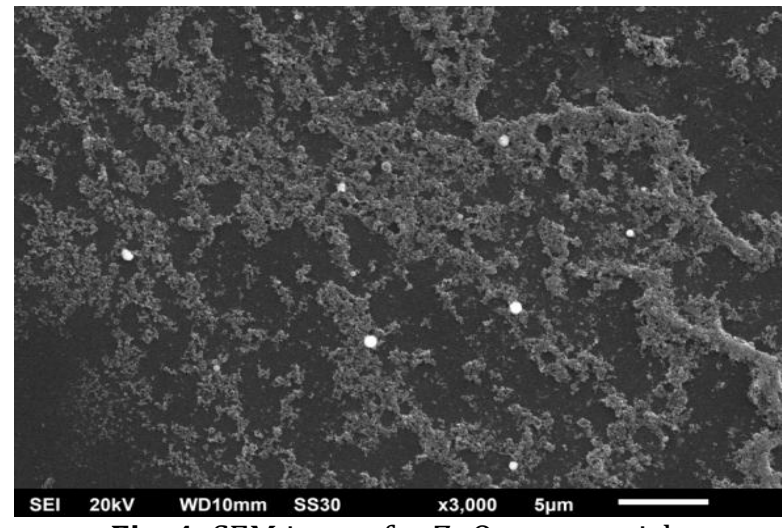

Fig. 4: SEM image for ZnO nanoparticles

\subsection{Effect of laser repetition rate}

Analysis of ZnONPs size distribution was utilized by imageJ software. The calculation technique is done by Otsu tresholding technique to measure the diameter of each circle pattern produced from SEM images in Figure 5. The higher repetition rate used can produce the smaller nanoparticles. This is because the greater repetition rate was used, it will cause particles in the colloid to experience fragmentation and decrease the size of the particle distribution. The surface of the sample and the synthesis medium through which the laser beam passes with a high level of laser shot repeatability will result in colloids being hit more often by laser pulses each time unit. This results in more photon energy hitting the surface of the sample and particles will be more fragmented compared to the low rate of laser shot repeatability. Therefore, particles produced with the use of high frequency laser shots have smaller sizes [28].

Table 1. The average diameter of the size of ZnONPs from processing ImageJ software

\begin{tabular}{cccc}
\hline Sample & $\begin{array}{c}\text { Repetition } \\
\text { Rate }(\mathrm{Hz})\end{array}$ & \multicolumn{2}{c}{ ZnONPs diameter } \\
\cline { 3 - 4 } & & $\begin{array}{l}\text { Average } \\
\text { diameter (nm) }\end{array}$ & $\begin{array}{c}\text { Deviation } \\
\text { standart (nm) }\end{array}$ \\
\hline $\mathrm{A}$ & 5 & 23.63 & 5.75 \\
$\mathrm{~B}$ & 10 & 12.13 & 4.41 \\
$\mathrm{C}$ & 15 & 5.59 & 4.74 \\
\hline
\end{tabular}

\subsection{Purity of ZnONPs}

ZnONPs content can be determined by Energy Dispersive X Ray (EDX) test. EDX analysis results show the presence of Zink (Zn), Oxygen (0), Carbon (C) and Silicon (Si) in ZnONPs colloid. These results of EDX characterization verified that the colloidal nanoparticles produced are high-purity zinc oxide nanoparticles because no others elements were detected on the surface of SiC sheet, except zinc and oxygen.

Zinc was detected in the EDX spectrum because the material used in the synthesis of $\mathrm{ZnO}$ nanoparticles was a zinc plate which had a high purity of $99.95 \%$. Silicon and Carbon peaks derived from those elements are main components of silica carbide ( $\mathrm{SiC}$ ) sheet. Oxygen contained in colloidal $\mathrm{ZnO}$ nanoparticles indicates the formation of $\mathrm{ZnO}$ compounds which are bonds between $\mathrm{Zn}$ and O. This is due to the absence of impurities in the EDX spectrum. The EDX spectrum of SiC sheet poured with ZnONPs is presented in Figure 5.

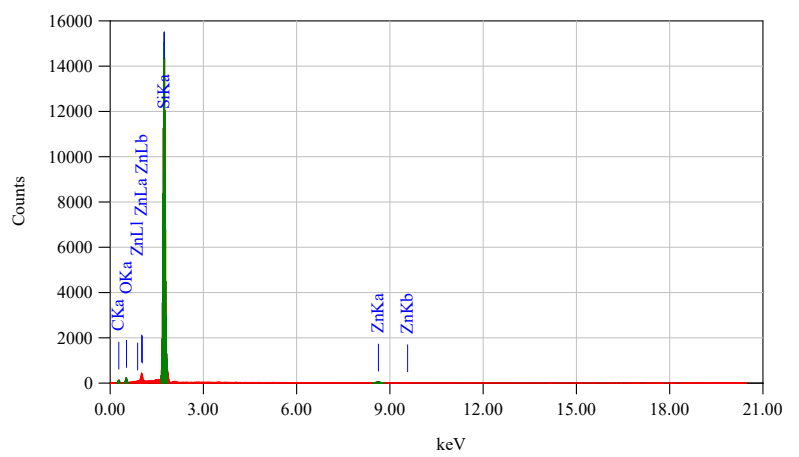

Fig. 5: EDX analysis

\subsection{FTIR analysis}

$\mathrm{ZnO}$ colloid nanoparticles showed transmittance bands at wave numbers $545 \mathrm{~cm}-1$ and $457 \mathrm{~cm}-1$. This corresponds to the peak of $\mathrm{ZnO}$ transmittance. The functional groups detected were the $\mathrm{O}-\mathrm{H}$ group in the band $3361 \mathrm{~cm}-1$ and the $\mathrm{C}=0$ group in the band $1646 \mathrm{~cm}-1$. The $0-\mathrm{H}$ group that was detected came from the synthesis medium in the form of aquades (H2O) that interact with the sample.

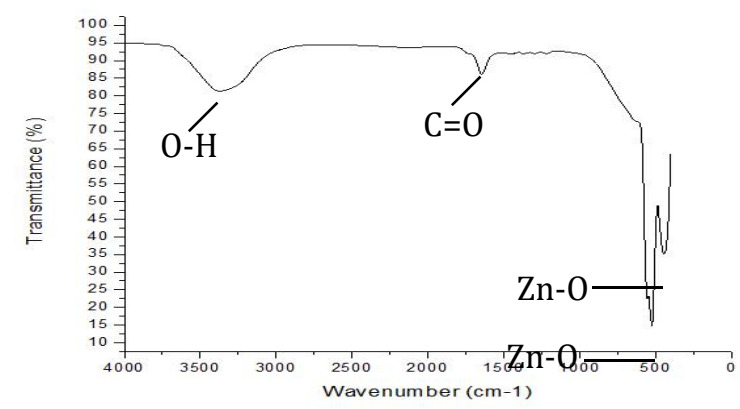

Fig. 6: The FTIR spectrum of $\mathrm{ZnO}$ colloid nanoparticles results from the synthesis of the pulse laser ablation method

\subsection{Photocatalys Mechanism of ZnONPs}

$\mathrm{ZnO}$ photocatalytic activity produced from electron and hole which come from semiconductor material. Energy band gap of ZnONPs in range 3.1-3.3 eV verified of ultraviolaet absorbance. ZnONPs is activated by irradiating UV light so that photocatalyst reaction occurred. Width of the energy band gap causes ZnONPs to capture more photon energy from UV light. In this study, energy band gap ZnONPs can be known from absorbance unit using Tauc plot method. Energy band gap of ZnONPs synthesized by pulse laser ablation method shown in Figure 7.

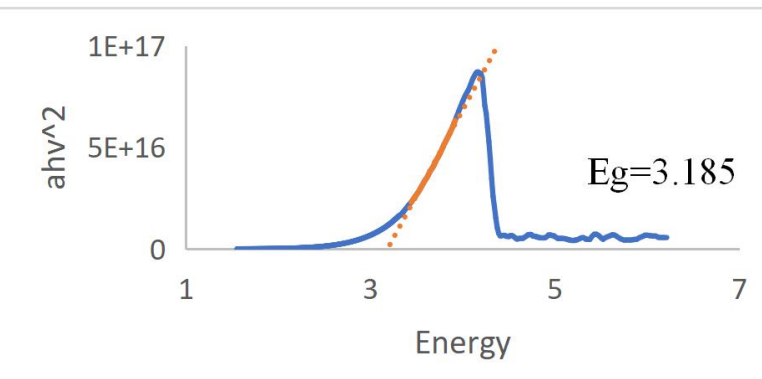

Fig. 7: Energy band gap of ZnONPs synthesized with (a) 5 $\mathrm{Hz}$, (b) $10 \mathrm{~Hz}$ and (c) $15 \mathrm{~Hz}$ 
The results of energy band gap verified that the colloidal ZnONPs correspondence with ultraviolet (UV) absorbance. ZnONPs semiconductor is irradiated with UV light during 90 minutes. UV rays come in contact with ZnONPs particles so they are able to excite electrons in a ground state.

In nanoparticles condition, the surface energy of $\mathrm{ZnO}$ activation is greater so that the energy produced is greater. The energy resulting from the excitation of these electrons caused the position of the electrons in the conduction band by producing electron (e) and hole (+) pairs so that they are referred to as photo excitation semiconductors. Photocatalyst reactions cause the formation of superoxide compounds releasing $\mathrm{O} 2$ and $\mathrm{OH}-$ radicals which can oxidize pollutants of heavy metals and bacteria [29].

3.8 Activation in Escherichia coli

ZnONPs can be used as antibacterial Escherichia coli. ZnO nanoparticles can damage the Escherichia coli membrane which causes leakage of cytosolic components and kills bacterial cells. $\mathrm{ZnO}$ can damage the bacterial cell membrane with hydrogen peroxide produced by $\mathrm{ZnO}$ or the proximity between $\mathrm{ZnO}$ and the surface of the bacteria [29].

The antibacterial activity test of $\mathrm{ZnO}$ nanoparticles against Escherichia coli bacteria was carried out by the liquid dilution method. The liquid dilution method was chosen because it is a simple method and is able to provide quantitative results showing the amount of $\mathrm{ZnO}$ nanoparticles needed to inhibit or kill Escherichia coli bacteria [29].

Antibacterial activity test using the liquid dilution method is done by dilution technique. Before making the test media, the first step is to determine the amount of Escherichia coli in agar nutrient media. The dilution process is carried out with a liquid medium in a row on tubes arranged in one rack. Each tube contains a mixture of media and colloidal $\mathrm{ZnO}$ nanoparticles with different concentrations of $40 \mathrm{ppm}, 60 \mathrm{ppm}$ and $80 \mathrm{ppm}$. The tube is then planted with a bacterial suspension containing $5.0 \mathrm{x}$ 108 CFU / mL bacterial cells. Furthermore, it was cultured in a tube medium and incubated at $37 \mathrm{oC}$ for $2 \times 24$ hours. Bacterial growth was observed by looking at turbidity in the tube caused by a bacterial inoculum [29].

Table 3. The amount and percentage of degradation of Escherichia coli bacteria

\begin{tabular}{lccc}
\hline Sample & $\begin{array}{l}\text { ZnONPs } \\
\text { concentra } \\
\text { te }(\mathrm{ppm})\end{array}$ & $\begin{array}{l}\text { The number of } \\
\text { Escherichia } \\
\text { coli }(\mathrm{CFU} / \mathrm{mL})\end{array}$ & $\begin{array}{l}\text { Persent } \\
\text { degradatio } \\
\mathrm{n}(\%)\end{array}$ \\
\hline Control & - & $5,00 \times 108$ & - \\
1 & 40 & $5,20 \times 107$ & 89,60 \\
2 & 60 & $1,12 \times 107$ & 97,76 \\
3 & 80 & $0,65 \times 107$ & 98,70 \\
\hline
\end{tabular}

Increasing ZnONPs concentrations indicate the number of ZnONPs in colloids is increase. As a result, nanoparticles interact more with Escherichia coli bacteria. The degradation process of Escherichia coli bacteria occurs by means of ZnONPs passing through the peptidoglycan bacteria Escherichia coli and is very susceptible to killing bacteria. Therefore, the higher the concentration of $\mathrm{ZnO}$ nanoparticles given, the more degraded Escherichia coli bacteria [29].

\section{Conclusions}

ZnONPs were synthesized using a pulse laser ablation method of varying the frequency of laser shots of $5 \mathrm{~Hz}, 10 \mathrm{~Hz}$ and $15 \mathrm{~Hz}$. The higher the frequency of laser shots used, the ZnONPs produced have a more concentrated color. The concentration of ZnONPs produced is higher with the use of higher laser shot frequencies as well. The XRD analysis results observed several peaks, namely at a value of $31.320 ; 34,930 ; 36.280 ; 40.07 \mathrm{o} ; 47,77 \mathrm{o}$ and $63,19 \mathrm{o}$ which are diffraction patterns by fields (100), (002), (101), (012), (110) and (013). The SEM image of ZnONPs shows that the ZnONPs produced have a spherical shape. The frequency of laser shots $5 \mathrm{~Hz}$, $10 \mathrm{~Hz}$ and $15 \mathrm{~Hz}$ produces ZnONPs with diameters of $23.63 \mathrm{~nm}, 12.13 \mathrm{~nm}$ and $5.59 \mathrm{~nm}$. The results of the EDX spectrum analysis show that there are only $\mathrm{Zn}$ and $\mathrm{O}$ atoms in the synthesized colloidal ZnONPs. FTIR results were observed that ZnONPs produced transmittance bands at wave numbers $457 \mathrm{~cm}-1$ and $545 \mathrm{~cm}-1$. The antibacterial activity test of ZnONPs on Escherichia coli bacteria was carried out by the liquid dilution method with variations in the concentration of ZnONPs at $40 \mathrm{ppm}, 60 \mathrm{ppm}$ and 80 ppm. ZnONPs with concentrations of $40 \mathrm{ppm}, 60$ $\mathrm{ppm}$ and $80 \mathrm{ppm}$ produced the percentage of degradation of Escherichia coli bacteria respectively at $89.60 \%, 97.76 \%$ and $98,70 \%$.

\section{References}

1. Owa, F.W., 2014, Water Pollution : source, effect, control and management,International letters of natural science, $3: 1-6$

2. Panagos, P., Van Liederke, M., Yigini, Y., Montanarella, L., 2013, Contaminated sites in europe : review of the current situation based on data collected through a european network, J. Environ, Public Health 201311

3. Best, E., Pamell, P., Couturier, J., Barbut, F., Le Bozec, A., Arnoldo, L., Madia, A., Brusaferro, S., Wilcox, M.H., 2018, Multicentre to examine the extent of enviromental contamination by potential bacteria pathogens including antibiotc resistant bacteria in hospital washrooms according to hand-drying method, Journal of Hospital Infection

4. Gadi, R., Kalra, S., Yadav, V.B., 2019, Study of heavy metal pollution, ecological risk and source apportionment in the surface water and sediments of the Jiangsu coastal region, China: A case study of the Sheyang Estuary, Journal of Enviromental Management 232, 803-817.

5. Chen, Y., Zhao, L., Wang, Z., Liu, Q., Xu, M., Zhao, Y., 2018, Study of heavy metal pollution, ecological risk and source apportionment in the surface water and sediments of the Jiangsu coastal region, China: A case study of the Sheyang Estuary, Marine Pollution Bulletin, 137, 601-609.

6. World Health Organization, 2017, Guidelines for drinking-water quality, fourth ed, incorpoating the 1st addendum.

7. Martins, C.C., Kolm, H.E., Gomes, K.V., Ishii, F.K., 2018, An integrated appraisement of multiple faecal indicator bacteria and sterols in the 
detection of sewage contamination in subtropical tidal creeks, International Journal of Hygiene and Enviromental Health

8. Bighiu, M.A., Halden, A.N., Geodkoop, W., Ottoson, J., 2019, Assesing microbial contamination and antibiotic resistant bacteria using zebra mussels (Dreissena polymorpha), Science Total Environment, 650, 2141-2149.

9. Al-Harassi, N., Al-Mayahi, A., Al-Ismaily, S., Sharooma, B., 2019, The role or urbanization in soil and groundwater contamination by heavy metals and phatogenic bacteria : A case study from Oman, Heliyon, 5, e01771.

10. Peixe, L., Novais, C., Pereira, J., Mourao, J., Campos, J., Antunes, P., 2018, Inflow water is a major source of trout farming contamination with Salmonella and multidrug resistant bacteria, Science of the Total Environment, 642, 11631171.

11. Wang, J., Ge, W., Zhu, L., Wang, J., Zhao, X., Wang, L., 2019, Macroclide and quinolone resistant bacteria and resistance gees as indicator of antibiotic resistance gene contamination in farmland soil with manure application, Ecological Indicators, 106, 105456

12. Trevisan, D., Vansteelant, J.Y., Dorioz, J.M., 2002, Survival and leaching of fecal bacteria after slurry spreading on mountain hay meadows : consequence for the management of water contamination risk, Water Research, 36, 275283.

13. Hofstra, N., Sokolova, E., Islam, M.M.M., 2018, Modelling of river faecal indicator bacteria dynamic as a basis for faecal conatmination reduction, Journal of Hidrology, 563, 1000-1008.

14. Nagaraju, G., Udayabhanu, Shivaraj, Prashanth, S.A., Shastri, M., Yathish, K.V., Anupama, C., Rangappa, D., 2017, Electrochemical heavy metal detection, photocatalytic, photoluminescence, biodiesel production and antibacterial activities of $\mathrm{Ag}-\mathrm{ZnO}$ nanomaterial, Materials Research Bulletin, 94, 54-63

15. Saleem, M.A., Salem, I.A., El-Ghobashy, M., 2017, The dual role of $\mathrm{ZnO}$ nanoparticles for efficient capture of heavy metals and Acid blue 92 from water, Journal of Molecular Liquids, 248, 527538.

16. Feng, J., Guo, X., Chen, Y., Lu, D., Niu, Z., Tou, F., Hou, L., Xu, J., Liu, M., Yang, Y., 2020, Timedependent effects of $\mathrm{ZnO}$ nanoparticles on bacteria in an estuarine aquatic environment, Science the Total Environment, 698, 134298

17. Bae, S., Joo, S.H., Toborek, M., 2019, Treatment of antibiotic-resistant bacteria by encapsulation of $\mathrm{ZnO}$ nanoparticles in an alginate biopolymer: Insights into treatment mechanisms, Journal of Hazardous Materials, 373, 122-130

18. Hilal, H. S., Jaber, A. F., Helal, M. H., Hamdan, S., Salman, M., Yousef, O., Alkowni, R., Zyoud, A., 2019, Solar light-driven complete mineralization of aqueous gram-positive and gram-negative bacteria with $\mathrm{ZnO}$ photocatalyst, Solar Energy, 180, 351-359

19. Pung, Swee-Yong, Le, A.T., Sreekantan, S., Atsunori, M., Huynh, D.P., 2018, Mechanism of removal of heavy metal ions by $\mathrm{ZnO}$ particles, Heliyon (5) e01440

Kim, M., Osone, S., Kim, T., Higashi, H. dan Seto, K. 2016. Synthesis of Nanoparticles by Laser Ablation. KONA powder and particle journal. Volume 34 : 80-90

Singh, S.C dan Gopal, R. 2007. Zinc nanoparticles in solution by laser ablation technique. Bulletin Material Science. 30 (3) : 291-293

Yu, J., Nan, J. dan Zeng, H. 2017. Size control of nanoparticles by multiple-pulse laser ablation. Applied Surface Science. 402 : 330-335.

20. Habibi-Yangjeh, A., Pirhashemi, M., Pouran, S.R., 2018, Review on the criteria anticipated for the fabrication of highly efficient $\mathrm{ZnO}$-based visiblelight-driven photocatalysts, Journal of Industrial and Engineering Chemistry, 62, 1-25

21. Yang, D. C., Lu, J., Abid, S.,Rupa, E.J., Ahn, J.C., Kaliraj, L., 2019, Synthesis of panos extract mediated $\mathrm{ZnO}$ nano-flowers as photocatalyst for industrial dye degradation by UV illumination, Journal of Photochemistry \& Photobiology, B: Biology, 199, 111588

22. Sanchez, L., Pavlovic, I., Cruz-Yusta, M., Balbuena, J., Pastor, A., 2019, ZnO on rice husk : A suistainable photocatalyst for urban air purification, Chemical Engineering Journal, 368, 659-667.

23. La Rosa, J. R. D., Gonzales-Casamachin, D. A., Luio-Orts, C.J., De Rio, D. A. D. H., MartinezVargas, D.X., Flores-Escamilla, G.A., Guzman, N. E. D., Ovando-Medina, V. M., Moctezuma-Velazquez, E., 2019, Visible-light photocatalytic degradation of acid violet 7 dye in a continuous annular reactor using $\mathrm{ZnO} / \mathrm{PPy}$ photocatalyst: Synthesis, characterization, mass transfer effect evaluation and kinetic analysis, Chemical Journal Engineering, 373, 325-337.

24. Raizada, P., Kumari, J., Shandilya, P., Singh,P., Kinetics of photocatalytic mineralization of oxytetracycline and ampicillin using activated carbon supported ZnO/ZnW04, Desalin. Water Treat. 79 (2017) 204-213

25. Raizada, P., Sudhaik, A., Singh, P., 2019, Photocatalytic water decontamination using graphene and ZnO coupled photocatalytic, Material Science for Energy Technologies, 2, 509-525.

26. Menendez, A dan Barcikowski, S. 2011. Hydrodynamic size ditribution of gold nanoparticles controlled by repetition rate during pulsed laser ablation method. Journal Applied Surface Science. 257 (9) : 4285 - 4290

27. Wang, C., Liu, L.L, Zhang, A.T, Xie P., Lu, J.J., dan Zou, X.T. 2012. Antibacterial effects of zinc oxide nanoparticles on Escherichia coli K88. African Journal of Biotechnology. Vol. 11(44), pp. 1024810254, ISSN: 1684-5315.

28. Jawetz, Melnick, Adelberg. 2007. Mikrobiologi Kedokteran Edisi 23. Jakarta : ISBN 978-979-448859-1

29. Mahmodi, S., Elmi, A dan Nezhadi, S.H. 2018. Copper nanoparticles as antibacterial agents. Molecular pharmaceutics and organic process research 6 (1) 